\title{
Transactions, Credit, and Central Banking in a Model of Segmented Markets
}

\author{
Stephen D. Williamson \\ Department of Economics \\ University of Iowa \\ Iowa City, IA 52240 \\ stephen-williamson@uiowa.edu \\ http://www.biz.uiowa.edu/faculty/swilliamson
}

February 2006

\begin{abstract}
A segmented markets model is constructed in which transactions are conducted using credit and currency. Goods market segmentation plays an important role, in addition to the role played by conventional segmentation of asset markets. An important novelty of the paper is to show how the diffusion of a money injection by the central bank depends not only on the interaction of agents in exchanging money for goods, but on the arrangements for clearing and settlement of credit instruments. The model permits open market operations, daylight overdrafts, reserve-holding, and overnight lending and borrowing, allowing us to consider a rich array of central banking arrangements and their implications.
\end{abstract}




\section{INTRODUCTION}

In this paper, we explore the implications of a tractable segmented markets model with credit and cash transactions, and with a rich array of possible central banking arrangements. As in traditional segmented markets models, this model has limited participation in particular asset markets, but a key element of the model is the segmentation of goods markets. The model permits open market operations, consumer credit transactions, daylight overdrafts, reserve-holding, overnight lending and borrowing, and clearing and settlement of consumer credit transactions. In the model, the transmission of monetary policy is in part determined by the rate of diffusion of a central bank money injection through the economy. In turn, this rate of diffusion depends first on the pattern of exchanges of cash and credit for goods, and second on the nature of arrangements for clearing and settlement of credit instruments. We explore the implications of different vehicles for accomplishing a central bank money injection, i.e. daylight overdrafts and open market operations. Further, we examine the implications of the payment of interest on reserves.

This model builds on Williamson (2006), which is a pure-currency framework where injections of outside money into the economy occur by way of lump-sum transfers. An important feature of that model is that there are two kinds of households, those who are connected, and those who are unconnected. Connected households can trade on asset markets, while unconnected households cannot. Further, and this is a novelty in that model, connected and unconnected households have "proximity" to different sets of goods markets, and this is critical to how monetary policy works. A Friedman rule for monetary policy is suboptimal, and an anticipated inflation effect on nominal interest rates tends to reinforce the liquidity effect, so that nominal interest rates are more volatile than in conventional segmented markets models. Monetary shocks have small effects on aggregate real quantities, but can have quantitatively important 
distributional effects.

This paper is related to the literature on asset market segmentation and monetary policy. One branch of the market segmentation literature is concerned with the development of general equilibrium versions of Tobin (1956) and Baumol (1952). In these models, some fraction of the population is engaged, or chooses to engage in, asset transactions at any point in time, and thus central bank actions in asset markets will initially directly affect only this "participating" population. A monetary injection by the central bank causes a redistribution of wealth which will in general result in short run changes in asset prices, employment, output, and the distribution of consumption across the population. The first models of this type were constructed by Grossman and Weiss (1983) and Rotemberg (1984). Later contributions include Alvarez and Atkeson (1997), and Alvarez, Atkeson, and Kehoe (2002), Alvarez, Atkeson and Edmond (2002), Chiu (2004) and Khan and Thomas (2005). Much, though not all, of this literature focusses on asset pricing implications, and a key feature of all these models is that all economic agents (participating or not) purchase goods in a single goods market.

Another related class of models deals with market segmentation in a representative household construct, and includes work by Lucas (1990), Fuerst (1992), and Christiano and Eichenbaum (1995). Fuerst's model, from which Christiano and Eichenbuam's is developed, obtains a nonneutrality of money through a cash-in-advance constraint faced by firms that applies to the purchase of labor services. This is quite different from what occurs in Tobin-Baumol-type models with endogenous labor supply.

Recent research in monetary theory is aimed at developing models of monetary economies that capture heterogeneity and the distribution of wealth in a manner that is tractable for analytical and quantitative work. One approach is to use a quasilinear utility function as in Lagos and Wright (2005), an approach that, under some 
circumstances, will lead to the result that economic agents optimally redistribute money balances uniformly among themselves whenever they have the opportunity. Another approach is to use a representative household with many agents, as in Shi (1997), in which (also see Lucas 1990) there can be redistributions of wealth within the household during the period, but these distribution effects do not persist. Work by Williamson (2005) and Shi (2004) uses the quasi-linear-utility and representativehousehold approaches, respectively, to study some implications of limited participation for optimal monetary policy, interest rates, and output. Other related work is Head and Shi (2003), and Head and Lapham (2005).

In the model constructed here, each household consists of a producer and a continuum of consumers. The consumers purchase goods in different markets, but are more likely to buy from households of their own type (connected or unconnected). Goods are purchased with credit, and these debts must be settled within the period. However, some debts are settled more quickly than others. If debt is settled quickly, then sales of goods can be used to finance other purchases by the household within the period. Otherwise, if goods are sold by a household in exchange for credit instruments that do not settle quickly, then the receipts from these sales cannot be spent until the following period.

A connected household can borrow and lend on bond markets (one-period and within-period), and the central bank also borrows and lends in these markets. If a period is interpreted as one day, then the central bank can engage in actions that can be interpreted as the extension of daylight overdrafts and intervention in the overnight credit market. Connected households hold outside money as reserve accounts with the central bank, and the central bank has the option of paying interest on these reserves. Unconnected households cannot borrow and lend in bond markets, and they hold outside money in the form of currency.

In general, connected and unconnected households sell goods at different prices in 
equilibrium. Further, a consumer pays a premium in a goods purchase where the debt exchanged for the goods takes longer to clear. A monetary shock not only produces a liquidity effect, but it affects relative prices. That is, a positive money shock tends to reduce the nominal interest rate, increase the relative price of goods sold by connected households, and reduce the relative price of goods exchanged for debt that takes a long time to clear.

In Section 2 we set up the model, while in Section 3 we set up the optimization problems of households and show how to construct an equilibrium. In Section 4 we determine the properties of an equilibrium. Section 5 is a conclusion.

\section{THE MODEL}

There is a continuum of infinitely-lived households with unit mass indexed by $i \in$ $[0,1]$. Each household consists of a producer and a continuum of consumers with unit mass, with a consumer indexed by $(i, j)$, with $j$ uniformly distributed on the interval $[0,1]$. The preferences of household $i$ are given by

$$
E_{0} \sum_{t=0}^{\infty} \beta^{t}\left[\int_{0}^{1} \log \left(c_{t}^{i}(j)\right) d j-v\left(n_{t}^{i}\right)\right]
$$

where $t$ indexes time, $0<\beta<1, c_{t}^{i}(j)$ is the consumption of consumer $j$ who is a member household $i$, and $n_{t}^{i}$ is the labor supply of the producer from household $i$. Assume that $v(\cdot)$ is twice continuously differentiable and strictly convex, with $v^{\prime}(0)=$ 0 and $v^{\prime}(\infty)=\infty$. The producer can supply an unlimited quantity of labor, and each unit of labor supplied yields one unit of the perishable consumption good.

Each household resides at a separate location. There is a fraction $\alpha$ of connected households, where $0<\alpha<1$. Connected households hold outside money as reserve accounts with the central bank, and also can trade on bond markets. Each connected household has $M_{0}^{1}$ units of outside money at the beginning of period 0 . The remaining fraction $1-\alpha$ of households are unconnected, in that they hold outside money in the 
form of divisible fiat currency and do not trade on bond markets. Each unconnected household has $M_{0}^{2}$ units of outside money in period 0 .

There is an absence-of-double-coincidence problem in this economy. Each household produces a distinct good, and the good that is produced by the producer in a household is not consumed by any of the consumers in that household. At the beginning of the period, each consumer in the household receives a preference shock, which determines the good that consumer wishes to consume during the period. Each consumer then travels to the location of the household that produces his or her desired good, purchases some quantity of that good (details of the exchange will be described later), consumes, and then returns home. A given consumer cannot visit more than one location, in addition to his or her home location, during a period.

For a consumer in a connected household, the probability that the consumer's desired good during the current period will be one sold by a connected household is $1-(1-\alpha) \pi$ and the probability that the desired good will be sold by an unconnected household is $(1-\alpha) \pi$. For a consumer from an unconnected household, the probability of that the consumer's desired good during the period is produced by an unconnected household is $1-\alpha \pi$, and the probability is $\alpha \pi$ that the consumer's desired good is produce by a connected household. For any consumer, the probability distribution for desired goods, conditional on the desired good being produced by a connected or unconnected household, is uniform. These meeting probabilities guarantee that the flows of consumers going from connected to unconnected households, and from unconnected to connected households, are equal each period. The parameter $\pi$ governs the interaction between connected households and unconnected households as groups. That is, if $\pi<1$ then the population of consumers arriving at a connected location will have a greater proportion of consumers from connected locations than would be observed arriving at an unconnected location, and similarly for unconnected locations. If $\pi=1$, then the population of consumers is identical across locations when 
consumers go shopping.

At the beginning of period $t$, consumers receive their preference shocks, and then purchase goods from the appropriate households with credit. That is, consumers exchange IOUs for goods, and the IOUs are settled during the period. For the purposes of clearing and settling IOUs, there are $N$ clearinghouses, indexed by $k=1,2, \ldots, N$, and each clearinghouse has $\frac{1}{N}$ households as members. Clearinghouse membership is determined at random, so that each clearinghouse has a mass of $\frac{1}{N}$ households as members, and for a given clearinghouse the fraction of connected member households is $\alpha$. Let $\gamma \equiv \frac{1}{N}$.

When consumers arrive to purchase goods from a producer in a household, the producer can determine in which cases the consumer's and producer's clearinghouses are the same, and in which cases these clearinghouses are different. The law of large numbers implies that each household will be selling to a fraction $\gamma$ of consumers who have the same clearinghouse membership, and to a fraction $1-\gamma$ whose clearinghouse membership is different. In general, goods will be sold at different prices to the two different groups of consumers, so that there are effectively two different markets for goods on which each individual household producer sells.

After households receive IOUs in exchange for the goods they have produced, the IOUs are sent to the appropriate clearinghouse; that is, an IOU issued by a particular household goes to the clearinghouse of which that household is a member. Thus, all of the IOUs issued by a household's consumers will at this point find their way back to the household's clearinghouse, and will represent debits on the household's account with its own clearinghouse, and the household will have received some IOUs from other household's that are also members of its clearinghouse, and these IOUs will constitute credits on the household's account with its clearinghouse. The household will also have submitted IOUs to clearinghouses of which it is not a member, and will therefore have credits against these other clearinghouses. At this point, settlement 
among clearinghouses takes place, and connected households and the central bank trade assets.

The sequence of events is as follows. First, connected households and the central bank trade assets, then each household settles its account with its own clearinghouse in outside money. For connected households this involves a transfer of reserve balances, and for unconnected households a transfer of currency. Next, each household settles with all other clearinghouses in a similar manner.

In the asset market on which connected households and the central bank trade, there are three assets: reserve balances, within-period nominal bonds, and one-period nominal bonds. In period $t$, a within-period bond sells for one unit of reserve balances and is a claim to $r_{t}$ units of reserve balances at the end of the period, while a oneperiod bond sells for one unit of reserve balances in period $t$ and pays off $R_{t+1}$ units of reserve balances in period $t+1$. One interpretation of these arrangements is that a period is one day, borrowing by a household within the period is a daylight overdraft with the central bank, and overnight borrowing and lending can be accomplished through combinations of within-period and one-period borrowing and lending.

The key consequences of these payments arrangements can be summarized in the constraints faced by households, which will differ somewhat depending on whether the household is connected or unconnected. We will consider equilibria where prices depend only on the method of payment and whether the seller of the good is a connected or unconnected household. Let $p_{t}^{1}$ and $q_{t}^{1}$ denote the prices at which a producer from a connected household sells when payment is made with an IOU that is cleared through the household's clearinghouse, or another clearinghouse, respectively. Similarly, $p_{t}^{2}$ and $q_{t}^{2}$ are the prices at which an unconnected household sells. The first 
constraint faced by the household is a finance constraint, which is

$$
\begin{aligned}
& {[1-(1-\alpha) \pi]\left[\gamma p_{t}^{1} c_{t}^{11}+(1-\gamma) q_{t}^{1} d_{t}^{11}\right] } \\
& +(1-\alpha) \pi\left[\gamma p_{t}^{2} c_{t}^{12}+(1-\gamma) q_{t}^{2} d_{t}^{12}\right]+b_{t+1}+f_{t} \\
\leq & i_{t} m_{t}^{1}+p_{t}^{1} x_{t}^{1}+R_{t} b_{t}-\tau_{1 t}
\end{aligned}
$$

In constraint (2), $c_{t}^{11}$ denotes the consumption of consumers from the connected household who buy from another connected household with a clearinghouse in common and $p_{t}^{1}$ is the money price of those goods, while $c_{t}^{12}$ is what is consumed by the consumers who buy from an unconnected household with a clearinghouse in common, at the price $p_{t}^{2}$. Similarly $d_{t}^{11}$ and $d_{t}^{12}$ denote what is consumed by consumers from a connected household who buy from connected and unconnected households respectively, but do not share a clearinghouse with the seller, and $q_{t}^{1}$ and $q_{t}^{2}$ are the corresponding prices. As well, $b_{t}$ is the quantity of one-period nominal bonds acquired by the household in period $t-1, f_{t}$ is the quantity of within-period nominal bonds purchased by the household, and $m_{t}^{1}$ is the household's beginning-of-period money balances. Here, $i_{t}$ denotes the gross nominal interest rate on reserve balances held from the end of period $t$ to the beginning of period $t+1$ (i.e. overnight). Finally, $x_{t}^{1}$ is the quantity of goods sold by the household's producer to consumers who are members of the same clearinghouse, and $\tau_{1 t}$ is a nominal lump-sum tax paid to the government. Thus, constraint (2) states that total household expenditure on goods and nominal bonds must be financed by the money balances with which the household begins the period, plus the IOUs acquired from consumers who share a clearinghouse with the household.

A connected household must satisfy its budget constraint, which is

$$
\begin{aligned}
& {[1-(1-\alpha) \pi]\left[\gamma p_{t}^{1} c_{t}^{11}+(1-\gamma) q_{t}^{1} d_{t}^{11}\right] } \\
& +(1-\alpha) \pi\left[\gamma p_{t}^{2} c_{t}^{12}+(1-\gamma) q_{t}^{2} d_{t}^{12}\right]+b_{t+1}+f_{t}+m_{t+1}^{1} \\
\leq & i_{t} m_{t}^{1}+p_{t}^{1} x_{t}^{1}+q_{t}^{1} y_{t}^{1}+R_{t} b_{t}+r_{t} f_{t}-\tau_{1 t}-\tau_{2 t}
\end{aligned}
$$


In constraint (3) $m_{t+1}^{1}$ is the quantity of money carried by the household into the next period, $y_{t}^{1}$ is the quantity of goods sold to consumers who do not have a clearinghouse in common with the household, $r_{t} f_{t}$ denotes the total nominal payoff on within-period bonds, and $\tau_{2 t}$ is a nominal lump-sum transfer paid to the government.

A key feature of the environment is that income earned by the household from the sale of goods for IOUs which clear on the second round of settlement cannot be spent until the following period. That is, constraint (2) is a type of cash-in-advance constraint.

Similarly, an unconnected household faces the finance constraint

$$
\alpha \pi\left[\gamma p_{t}^{1} c_{t}^{21}+(1-\gamma) q_{t}^{1} d_{t}^{21}\right]+(1-\alpha \pi)\left[\gamma p_{t}^{2} c_{t}^{22}+(1-\gamma) q_{t}^{2} d_{t}^{22}\right] \leq m_{t}^{2}+p_{t}^{2} x_{t}^{2}
$$

and the budget constraint

$$
\alpha \pi\left[\gamma p_{t}^{1} c_{t}^{21}+(1-\gamma) q_{t}^{1} d_{t}^{21}\right]+(1-\alpha \pi)\left[\gamma p_{t}^{2} c_{t}^{22}+(1-\gamma) q_{t}^{2} d_{t}^{22}\right]+m_{t+1}^{2} \leq m_{t}^{2}+p_{t}^{2} x_{t}^{2}+q_{t}^{2} y_{t}^{2}
$$

Note that, in contrast to the connected household, the unconnected household does not trade bonds, receives no government transfers, and does not receive interest on its outside money balances, which are in the form of currency.

There are a number of restrictions in this model on the types of assets that can be traded, and who can trade these assets. First, contingent claims markets are absent. As we will see, in the equilibria that we examine, all connected households will be identical, and all unconnected households will be identical, but connected and unconnected households would want to trade contingent claims if they could. However, the only interaction between these households is in meetings between consumers and households. It is assumed that anonymity holds in these meetings, i.e. as agents cannot be identified, contingent claims contracts cannot be enforced. Further, clearinghouses are not able to verify particular contingencies and so they cannot act as contingent-claim intermediaries. Second, unconnected households cannot trade 
bonds, and bonds (at least some of them) cannot be used in settlement. Since bonds must be purchased with reserve balances, the payoffs are in reserve balances, and unconnected households cannot hold reserve balances, these households therefore cannot hold bonds either. We assume that the government prohibits the issue of liabilities that have the features of government-issued fiat currency, and so bonds cannot be intermediated and used in transactions. Constraint (2) could be relaxed if a household's clearinghouse would accept the IOUs of non-member households in settlement. However, we assume that a clearinghouse does not have the means to verify the authenticity of IOUs other than the ones issued by its members.

To normalize, we will suppose that the initial aggregate quantity of outside money is unity, i.e.

$$
\alpha M_{0}^{1}+(1-\alpha) M_{0}^{2}=1
$$

and there are initially no outstanding government bonds. As well, all interest on government bonds in periods $1,2, \ldots$ is financed by the lump-sum transfers, so that the aggregate quantity of nominal government liabilities is fixed at unity forever. Our principal concern is in determining the effects of changes in the the composition of the government's debt, i.e. the effects of monetary policy. Let $M_{t}^{1}\left(M_{t}^{2}\right)$ denote the stock of money per capita supplied to connected (unconnected) households at the beginning of period $t, B_{t}$ the quantity of one-period government bonds per connected household maturing in period $t$, and $F_{t}$ the quantity of within-period government bonds maturing in period $t$. The government's budget constraint is then

$$
\alpha M_{t+1}^{1}+(1-\alpha) M_{t+1}^{2}=i_{t} \alpha M_{t}^{1}+(1-\alpha) M_{t}^{2}-\alpha B_{t+1}+R_{t} \alpha B_{t}+\left(r_{t}-1\right) \alpha F_{t}-\alpha \tau_{1 t}-\alpha \tau_{2 t},
$$

where $B_{0}=0$. The lump-sum taxes that finance interest on the government debt are levied in such a way as to have no distributional consequences, that is

$$
\tau_{1 t}=\left(R_{t}-1\right) B_{t}+\left(i_{t}-1\right) M_{t}^{1}
$$


and

$$
\tau_{2 t}=\left(r_{t}-1\right) F_{t}
$$

The government chooses $i_{t}, B_{t+1}, F_{t}, \tau_{1 t}$, and $\tau_{2 t}$ at the beginning of period $t$, possibly in a random fashion. The gross interest rates $R_{t}$ and $r_{t}$ are then market-determined, and (6), (7), and (8) then determine the total quantity of aggregate outside money in period $t+1$ on the left-hand side of (6).

\section{OPTIMIZATION AND EQUILIBRIUM}

In this section, our goals are to characterize the solution to the households' optimization problems, and impose equilibrium conditions.

For a connected household, given the household's objective function (1) and its constraints (2) and (3), and assuming an interior solution (which we must have in equilibrium), intratemporal optimization gives

$$
\frac{1}{p_{t}^{1} c_{t}^{11}}=\frac{1}{q_{t}^{1} d_{t}^{11}}=\frac{1}{p_{t}^{2} c_{t}^{12}}=\frac{1}{q_{t}^{2} d_{t}^{12}}=\frac{v^{\prime}\left(x_{t}^{1}+y_{t}^{1}\right)}{p_{t}^{1}}=\lambda_{t}^{1}+\frac{v^{\prime}\left(x_{t}^{1}+y_{t}^{1}\right)}{q_{t}^{1}}=\frac{r_{t} v^{\prime}\left(x_{t}^{1}+y_{t}^{1}\right)}{q_{t}^{1}}
$$

where $\lambda_{t}^{1}$ denotes the multiplier associated with the household's finance constraint (2). In (9), the log utility functions of consumers imply that the household will

equalize expenditures across the household's consumers at the optimum. This will give us considerable mileage in the analysis. Intertemporal optimization by a connected household gives

$$
\frac{v^{\prime}\left(x_{t}^{1}+y_{t}^{1}\right)}{q_{t}^{1}}=\beta i_{t+1} E_{t}\left(\frac{1}{p_{t+1}^{1} c_{t+1}^{11}}\right)
$$

and

$$
\frac{1}{p_{t}^{1} c_{t}^{11}}=\beta R_{t+1} E_{t}\left(\frac{1}{p_{t+1}^{1} c_{t+1}^{11}}\right) .
$$

Similarly, for unconnected households, given (1), (4), and (5), the analogs of (9) 
and (10) are

$$
\begin{aligned}
& \frac{1}{p_{t}^{1} c_{t}^{21}}=\frac{1}{q_{t}^{1} d_{t}^{21}}= \frac{1}{p_{t}^{2} c_{t}^{22}}=\frac{1}{q_{t}^{2} d_{t}^{22}}=\frac{v^{\prime}\left(x_{t}^{2}+y_{t}^{2}\right)}{p_{t}^{2}}=\lambda_{t}^{2}+\frac{v^{\prime}\left(x_{t}^{2}+y_{t}^{2}\right)}{q_{t}^{2}} \\
& \frac{v^{\prime}\left(x_{t}^{2}+y_{t}^{2}\right)}{q_{t}^{2}}=\beta E_{t}\left(\frac{1}{p_{t+1}^{2} c_{t+1}^{22}}\right)
\end{aligned}
$$

Next, in equilibrium the market clears for goods sold in connected locations for IOUs that clear early,

$$
\gamma\left\{[1-(1-\alpha) \pi] c_{t}^{11}+(1-\alpha) \pi c_{t}^{21}\right\}=x_{t}^{1}
$$

for goods sold in connected locations for IOUs that clear late,

$$
(1-\gamma)\left\{[1-(1-\alpha) \pi] d_{t}^{11}+(1-\alpha) \pi d_{t}^{21}\right\}=y_{t}^{1}
$$

and for goods sold in unconnected locations for IOUs that clear early and late, respectively,

$$
\begin{gathered}
\gamma\left[\alpha \pi c_{t}^{12}+(1-\alpha \pi) c_{t}^{22}\right]=x_{t}^{2}, \\
(1-\gamma)\left[\alpha \pi d_{t}^{12}+(1-\alpha \pi) d_{t}^{22}\right]=y_{t}^{2}
\end{gathered}
$$

Finally, asset markets clear, that is

$$
B_{t}=b_{t}, F_{t}=f_{t}, M_{t}^{1}=m_{t}^{1}, M_{t}^{2}=m_{t}^{2}
$$

\section{ANALYSIS}

In this section, given the characterization of a competitive equilibrium from the previous section, we obtain some results concerning prices and the effects of open market operations.

First, note from (9) and (12) that, $p_{t}^{i}=q_{t}^{i}$ if and only if $\lambda_{t}^{i}=0$ and $p_{t}^{i}<q_{t}^{i}$ if and only if $\lambda_{t}^{i}>0$, for $i=1,2$. Therefore, a consumer will pay a premium if he or she purchases goods with IOUs that clear late, if and only if the finance constraint 
binds. That is, so long as there is a binding finance constraint, then all income received by the household from the sale of goods for early-clearing IOUs is spent in the current period. However, income received from selling goods in exchange for late clearing IOUs cannot be spent until the following period. Therefore, the household will demand a premium to accept a late-clearing IOU. As well, from (9) we have

$$
r_{t}=\frac{q_{t}^{1}}{p_{t}^{1}}
$$

where $r_{t}$ is the gross nominal interest rate on within-period bonds. Therefore, the within-period nominal interest rate is greater than zero if and only if consumers pay a premium when they make a purchase with a late-clearing IOU, i.e. if and only if the finance constraint binds for connected households.

We will assume for now (and check this later) that the finance constraints (2) and (4) always bind. Then, letting $z_{t}^{1}\left(z_{t}^{2}\right)$ denote nominal expenditure in period $t$ by a connected (unconnected) household, and given (2), (4), (6), (7), (8), and (18), we get

$$
\begin{gathered}
z_{t}^{1}=p_{t}^{1} x_{t}^{1}+M_{t}^{1}+B_{t}-B_{t+1}-F_{t} \\
z_{t}^{2}=p_{t}^{2} x_{t}^{2}+M_{t}^{2} .
\end{gathered}
$$

From (9), (12), (14), and (16), nominal expenditures in connected and unconnected locations, respectively, where payment is in early-clearing IOUs, is given by

$$
\begin{gathered}
p_{t}^{1} x_{t}^{1}=\gamma\left\{[1-(1-\alpha) \pi] z_{t}^{1}+(1-\alpha) \pi z_{t}^{2}\right\}, \\
p_{t}^{2} x_{t}^{2}=\gamma\left[\alpha \pi z_{t}^{1}+(1-\alpha \pi) z_{t}^{2}\right]
\end{gathered}
$$

Then, substituting in (20) and (21) for $p_{t}^{1} x_{t}^{1}$ and $p_{t}^{2} x_{t}^{2}$ using (22) and (23), and solving for $z_{t}^{1}$ and $z_{t}^{2}$, we obtain

$$
(1-\gamma) z_{t}^{1}=\frac{[1-\gamma(1-\alpha \pi)]\left[M_{t}^{1}+B_{t}-B_{t+1}-F_{t}\right]+(1-\alpha) \pi \gamma M_{t}^{2}}{[1-\gamma(1-\pi)]}
$$




$$
(1-\gamma) z_{t}^{2}=\frac{\alpha \pi \gamma\left[M_{t}^{1}+B_{t}-B_{t+1}-F_{t}\right]+\{1-\gamma[1-(1-\alpha) \pi]\} M_{t}^{2}}{[1-\gamma(1-\pi)]}
$$

In (24) and (25), note that $M_{t}^{1}+B_{t}-B_{t+1}-F_{t}$ is the quantity of outside money available to a connected household at the beginning of period $t$ after the the government makes asset trades, while $M_{t}^{2}$ is the quantity of outside money available to an unconnected household. Then, (24) shows that the nominal expenditures by a connected household on goods purchased with IOUs that clear late, $(1-\gamma) z_{t}^{1}$, equals a weighted average of the quantities of outside money available to connected and unconnected households. That is, when consumers from an unconnected household make purchases from a connected household, some of the receipts of the connected household are available to spend during the period. Since nominal expenditure by unconnected households will tend to increase with $M_{t}^{2}$, therefore nominal expenditure by connected households will tend to increase with $M_{t}^{2}$ as well, as we see in (24). Note that the weight on $M_{t}^{2}$ in equation (24) is increasing in $(1-\alpha) \pi$, the fraction of consumers buying from a connected household who come from an unconnected household. As well, the weight on $M_{t}^{2}$ in equation (24) is increasing in $\gamma$, the fraction of goods transactions that are settled early in the period. Equation (25) shows a similar relationship to (25) for an unconnected household rather than a connected one.

Next, we can determine the quantities of money per household in each location in period $t+1$. Given that the finance constraints (2) and (4) bind, from (2)-(5), (6), (7), (8), and (18), we get

$$
\begin{gathered}
M_{t+1}^{1}=q_{t}^{1} y_{t}^{1}+F_{t}, \\
M_{t+1}^{2}=q_{t}^{2} y_{t}^{2} .
\end{gathered}
$$

Therefore, from (9), (12), (15), (17), (24), and (25), we obtain

$$
M_{t+1}^{1}=M_{t}^{1}+B_{t}-B_{t+1}-\frac{(1-\alpha) \pi\left[M_{t}^{1}+B_{t}-B_{t+1}-F_{t}-M_{t}^{2}\right]}{[1-\gamma(1-\pi)]},
$$




$$
M_{t+1}^{2}=M_{t}^{2}+\frac{\alpha \pi\left[M_{t}^{1}+B_{t}-B_{t+1}-F_{t}-M_{t}^{2}\right]}{[1-\gamma(1-\pi)]} .
$$

Equations (26) and (27) show that, if the quantity of outside money available to spend per connected households is greater than the quantity available per unconnected households, then money will flow from connected to unconnected households, and vice-versa. Note, in equations (26) and (27) that money flows are larger the larger is $\pi$ and the larger is $\gamma$. That is, $\pi$ and $\gamma$ determine the speed of diffusion of an outside money injection by the central bank, which can occur either through an open market purchase $\left(B_{t}-B_{t+1}\right)$ or a daylight overdraft $\left(-F_{t}\right)$. The parameter $\pi$ governs the degree to which households purchase goods from other households of the same type. Note from (26) and (27) that, if $\pi=1$, then diffusion occurs in one period, that is

$$
M_{t+1}^{1}=\alpha\left(M_{t}^{1}+B_{t}-B_{t+1}\right)+(1-\alpha) M_{t}^{2}+(1-\alpha) F_{t}=M_{t+1}^{2}-F_{t}
$$

The parameter $\gamma$ is the fraction of goods transactions volume that clears early in the period, so that an increase in $\gamma$ also speeds diffusion. Setting $\gamma=1$ in (26) and (27) gives the same result as setting $\pi=1$, i.e. diffusion occurs in one period. However, the economy with $\gamma=1$ is one where outside money is not needed as a medium of exchange.

Now, to solve for an equilibrium, first let $\psi_{t}^{1}$ and $\psi_{t}^{2}$ denote total nominal expenditure on the goods produced by a connected and unconnected household, respectively. From (24) and (25) we get

$$
\begin{aligned}
\psi_{t}^{1}= & {[1-(1-\alpha) \pi] z_{t}^{1}+(1-\alpha) \pi z_{t}^{2} } \\
= & \frac{[1-\gamma(1-\pi)-(1-\alpha) \pi]\left(M_{t}^{1}+B_{t}-B_{t+1}-F_{t}\right)+(1-\alpha) \pi M_{t}^{2}}{(1-\gamma)[1-\gamma(1-\pi)]} \\
\psi_{t}^{2} & =\alpha \pi z_{t}^{1}+(1-\alpha \pi) z_{t}^{2} \\
& =\frac{\alpha \pi\left(M_{t}^{1}+B_{t}-B_{t+1}-F_{t}\right)+[1-\gamma(1-\pi)-\alpha \pi] M_{t}^{2}}{(1-\gamma)[1-\gamma(1-\pi)]}
\end{aligned}
$$


Then, from (10), (22), (28), and since $q_{t}^{1} y_{t}^{1}(1-\gamma)=p_{t}^{1} x_{t}^{1} \gamma$, we get

$$
\frac{v^{\prime}\left(x_{t}^{1}+y_{t}^{1}\right) y_{t}^{1}}{1-\gamma}=\beta i_{t+1} \psi_{t}^{1} E_{t}\left(\frac{1}{z_{t+1}^{1}}\right)
$$

and (10) and (22) gives

$$
\frac{v^{\prime}\left(x_{t}^{1}+y_{t}^{1}\right) x_{t}^{1}}{\gamma}=\frac{\psi_{t}^{1}}{z_{t}^{1}}
$$

Similarly, for unconnected households, we obtain

$$
\frac{v^{\prime}\left(x_{t}^{2}+y_{t}^{2}\right) y_{t}^{2}}{1-\gamma}=\beta \psi_{t}^{2} E_{t}\left(\frac{1}{z_{t+1}^{2}}\right)
$$

and (10) and (22) gives

$$
\frac{v^{\prime}\left(x_{t}^{2}+y_{t}^{2}\right) x_{t}^{2}}{\gamma}=\frac{\psi_{t}^{2}}{z_{t}^{2}}
$$

and (32) and (33) solve for $x_{t}^{2}$ and $y_{t}^{2}$. Further, from (9) and (11) nominal interest rates are determined by

$$
\frac{1}{R_{t+1}}=\beta z_{t}^{1} E_{t}\left(\frac{1}{z_{t+1}^{1}}\right)
$$

and

$$
r_{t}=\frac{R_{t+1}}{i_{t+1}}
$$

A monetary policy is a stochastic process for $\left\{B_{t+1}, F_{t}, i_{t+1}\right\}_{t=0}^{\infty}$ given $B_{0}=0$ and satisfying

$$
M_{t}^{1}+B_{t}-B_{t+1}-F_{t}>0
$$

and

$$
1 \leq i_{t+1} \leq R_{t+1}
$$

for all $t$, which then determines a stochastic process for $\left\{M_{t}^{1}, M_{t}^{2}\right\}_{t=1}^{\infty}$ given $M_{0}^{1}$ and $M_{0}^{2}$ from (26) and (27). Then, we can use (24), (25), (28), and (29) to determine $\left\{z_{t}^{1}, z_{t}^{2}, \psi_{t}^{1}, \psi_{t}^{2}\right\}$, which is an exogenous stochastic process. Then, the mathematics involved in the solution is very simple. Equations (30) and (31) solve jointly for $x_{t}^{1}$ 
and $y_{t}^{1}$, equations (32) and (33) solve jointly for $x_{t}^{2}$ and $y_{t}^{2}(34)$ solves for $R_{t+1}$ and (35) solves for $r_{t}$, all for $t=0,1,2, \ldots$. Then, the consumption allocation is given by

$$
\begin{aligned}
& c_{t}^{i j}=x_{t}^{j} \frac{z_{t}^{i}}{\psi_{t}^{j}}, \text { for } i, j=1,2, \\
& d_{t}^{i j}=y_{t}^{j} \frac{z_{t}^{i}}{\psi_{t}^{j}}, \text { for } i, j=1,2 .
\end{aligned}
$$

\section{CONCLUSION}

We have constructed a tractable model where there are alternative payments arrangements for purchasing goods, and where the central bank can use different vehicles to inject outside money into the private economy. All goods are purchased with IOUs, but some IOUs clear more quickly than others. As a result, outside money is useful in settling debts. However, only connected households can borrow and lend on bond markets and hold outside money as reserve balances with the central bank.

Because of goods market segmentation, prices are in general different in different markets, and a central bank money injection will affect relative prices in the short run across goods markets. Further, consumers pay a premium in a goods purchase if the IOU with which the good is purchased does not clear quickly. Thus, in a particular market, prices depend on the payment instrument used, and relative prices in any given market change in response to a money injection.

The rate of diffusion of a money injection through the economy determines the persistence in the effects of monetary policy and its quantitative initial impact. The rate of diffusion increases as the probability that different types of households trade increases, and it change with the arrangements for clearing and settling credit instruments. 


\section{REFERENCES}

Alvarez, F. and Atkeson, A. 1997. "Money and Exchange Rates in the GrossmanWeiss-Rotemberg Model," Journal of Monetary Economics 40, 619-40.

Alvarez, F., Atkeson, A., and Kehoe, P. 2002. "Money, Interest Rates, and Exchange Rates with Endogenously Segmented Markets," Journal of Political Economy 110, 73-112.

Baumol, W. 1952. "The Transactions Demand for Cash: An Inventory Theoretic Approach," Quarterly Journal of Economics 66, 545-556.

Chiu, J. 2005. "Endogenously Segmented Asset Market in an Inventory Theoretic Model of Money Demand," working paper, University of Western Ontario.

Christiano, L. and Eichenbaum, M. 1995. "Liquidity Effects, Monetary Policy, and the Business Cycle," Journal of Money, Credit, and Banking 27, 1113-1136.

Cooley, T. and Hansen, G. 1989. "The Inflation Tax in a Real Business Cycle Model," American Economic Review 79, 733-748.

Grossman, S. and Weiss, L. 1983. "A Transactions-Based Model of the Monetary Transmission Mechanism," American Economic Review 73, 871-880.

Head, A. and Lapham, B. 2005. "Limited Participation, Market Power and Inflation Dynamics," working paper, Queen's University.

Head, A. and Shi, S. 2003. "A Fundamental Theory of Exchange Rates and Direct Currency Trades," Journal of Monetary Economics 50, 1555-1592.

Lagos, R., and Wright, R. 2005. "A Unified Framework for Monetary Theory and Policy Analysis," Journal of Political Economy 113, 463-484. 
Lucas, R. 1990. "Liquidity and Interest Rates," Journal of Economic Theory 50, 237-264.

Lucas, R. 2000. "Inflation and Welfare," Econometrica 68, 247-274.

Rotemberg, J. 1984. "A Monetary Equilibrium Model with Transactions Costs," Journal of Political Economy 92, 40-58.

Shi, S. 1997. "A Divisible Model of Fiat Money," Econometrica 65, 75-102.

Shi, S. 2004. "Liquidity, Interest Rates, and Output," working paper, University of Toronto.

Tobin, J. 1956. "The Interest-Elasticity of Transactions Demand for Cash," Review of Economics and Statistics 38, 241-247.

Williamson, S. 2005. "Search, Limited Participation, and Monetary Policy," forthcoming, International Economic Review.

Williamson, S. 2006. "Monetary Policy and Distribution," working paper, University of Iowa. 